\title{
Workplace violence against physicians and nurses in Palestinian public hospitals: a cross-sectional study
}

Mohamad Kitaneh and Motasem Hamdan ${ }^{*}$

\begin{abstract}
Background: Violence against healthcare workers in Palestinian hospitals is common. However, this issue is under researched and little evidence exists. The aim of this study was to assess the incidence, magnitude, consequences and possible risk factors for workplace violence against nurses and physicians working in public Palestinian hospitals.
\end{abstract}

Methods: A cross-sectional approach was employed. A self-administered questionnaire was used to collect data on different aspects of workplace violence against physicians and nurses in five public hospitals between June and July 2011. The questionnaires were distributed to a stratified proportional random sample of 271 physicians and nurses, of which 240 (88.7\%) were adequately completed. Pearson's chi-square analysis was used to test the differences in exposure to physical and non-physical violence according to respondents' characteristics. Odds ratios and 95\% confidence intervals were used to assess potential associations between exposure to violence (yes/no) and the respondents' characteristics using logistic regression model.

Results: The majority of respondents (80.4\%) reported exposure to violence in the previous 12 months; 20.8\% physical and $59.6 \%$ non-physical. No statistical difference in exposure to violence between physicians and nurses was observed. Males' significantly experienced higher exposure to physical violence in comparison with females. Logistic regression analysis indicated that less experienced (OR: 8.03; 95\% Cl 3.91-16.47), and a lower level of education (OR: 3; 95\% Cl 1.29-6.67) among respondents meant they were more likely to be victims of workplace violence than their counterparts. The assailants were mostly the patients' relatives or visitors, followed by the patients themselves, and co-workers. Consequences of both physical and non-physical violence were considerable. Only half of victims received any type of treatment. Non-reporting of violence was a concern, main reasons were lack of incident reporting policy/procedure and management support, previous experience of no action taken, and fear of the consequences.

Conclusions: Healthcare workers are at comparably high risk of violent incidents in Palestinian public hospitals. Decision makers need to be aware of the causes and potential consequences of such events. There is a need for intervention to protect health workers and provide safer hospital workplaces environment. The results can inform developing proper policy and safety measures.

Keywords: Workplace violence, Hospitals, Health care workers, Nurses and physicians, Palestine

\footnotetext{
* Correspondence: mhamdan@med.alquds.edu

Faculty of Public Health, Al-Quds University, Jerusalem, P.O.Box 51000,

occupied Palestinian territory
} 


\section{Background}

Workplace violence in the health sector is a worldwide concern with healthcare workers being at high risk of being victims [1]. Violence includes any physical assault, verbal abuse or threatening behavior occurring in a workplace setting [2]. Both physical and non-physical violence against health care workers is a major problem affecting their health and productivity. Moreover, the consequences of workplace violence in the health sector have a significant impact on the effectiveness of health systems, especially in developing countries [3].

Although health care providers are increasingly concerned about the escalating incidence of workplace violence, there is a lack of evidence to support this concern due to low violence reporting rates [4]. In the Arab region also there is relatively limited research conducted on violence in health care settings [5-11].

Palestine is a country in chronic conflict and economic emergency [12]. The Palestinian Ministry of Health $(\mathrm{MoH})$ is the main provider of health care services. The majority of the population is covered by the governmental health insurance scheme by which they are entitled to public services. This has increased the burden on limited public services, where most of public hospitals have high rates of service utilization and bed occupancy [13]. Besides routine care, these hospitals act as the main source of care for patients and injured people during political emergencies. Public hospitals are also known to suffer from many problems including understaffing and the frequent shortages of medicines and supplies which cause patients to wait for a long time before receiving services [14]. It is believed that these problems may cause violence against physicians and nurses. However, there remains a lack of adequate research evidence about the issue.

This study aims to assess the incidence, magnitude, and possible risk factors for workplace violence against nurses and physicians working in public hospitals in Palestine. It also examines the consequences of violence, professionals' incident reporting patterns, and existing violence prevention and safety measures from health care workers' perspectives. The study results can support the development of sound policy and strategies to prevent and manage work place violence against health workers in the country.

\section{Methods}

\section{Study setting}

There are eleven general $\mathrm{MoH}$ hospitals in the West Bank (WB). The study setting consisted of five of these public hospitals located in the five northern districts (Tulkarem, Nablus, Jenin, Qalqilya, Salfit) in the WB. The total number of the studied hospitals beds was
554 beds; about $41 \%$ of the total public beds in the WB [13].

\section{Study design}

A cross-sectional design was adopted. Data were collected between June and July 2011. The study population $(\mathrm{n}=928)$ consisted of all the licensed physicians $(\mathrm{n}=$ 292) and nurses $(n=636)$ who work on a full-time basis and with at least one year experience in these hospitals. Trainees or interns were excluded from the study. The population of the study was about $45 \%$ of the total physicians and nurses working in the $\mathrm{MoH}$ hospitals in the WB [13].

A proportionate stratified random sample was obtained from the study population. The total sample size was calculated from the study population $(\mathrm{n}=928)$ based on the assumptions of $\alpha=0.05$, confidence interval $95 \%$, and margin of error 0.05 . The targeted 5 hospitals represented strata. The sample size from each stratum was proportional to its size in the study population, and within that the number of physicians and nurses were also proportionally calculated. This resulted in a sample of 271, composed of 84 physicians (31\%) and 187 nurses (69\%). The sample was randomly selected from each hospital.

\section{Study instrument}

In this study work related violence is defined as any activity associated with the job or any event that occurs in the work environment that involves the intentional use of physical force or emotional abuse against an employee and results in physical or emotional injury and consequences $[15,16]$. Moreover, non-physical assault includes threat, sexual harassment, and verbal abuse [16].

The study instrument was prepared on the basis of the questionnaires used in two earlier studies [15,16]. The instrument was modified to fit the objectives of the study and the Palestinian hospitals context and was translated into Arabic. It was reviewed by five experts (nurses and physicians) to enhance its validity. Experts assessed the clarity, relevancy, comprehensiveness, and sensitivity of the tool to the culture. Basically, the expert comments were about the definitions of the violence, in specific the sexual violence, and clarity of some questions. The modified questionnaire was then pilot tested with 20 participants (physicians and nurses), who were excluded from the study sample.

The questionnaire gathered information on the following areas; socio-demographic data of the participants, exposure to physical and non-physical violence in the past 12 months, characteristics of perpetrators, magnitude and consequence of violence, incident reporting, availability of policies/procedures, training programmes, and safety measures in the workplace. 


\section{Data collection}

A self-administered questionnaire was distributed to 271 nurses and physicians. Permission to conduct the study and ethical approval were obtained from the $\mathrm{MoH}$ and Al-Quds University review board. Written consent was also obtained from participants after explaining the aim and assuring the confidentiality of the study; 249 questioners were completed, of which 240 were adequately completed. The general response rate was $88.7 \%$; for physicians $95.2 \%$ and for nurses $85.5 \%$ respectively.

\section{Data analysis}

Descriptive statistics were completed relating to the respondents' characteristics. Pearson's chi-square analysis was used to test the differences in exposure to violence (physical and non-physical violence) according to respondents' characteristics. Crude odds ratios and 95\% confidence intervals were used to assess potential associations between exposures to violence in general (yes/no) and respondents' characteristics including gender, profession, age, years of experience, educational level, hospital department. Adjustment was then made for the same pre-mentioned covariates using a logistic regression model; the dependent variable being exposure to violence (yes, no). Data was analyzed using the Statistical Package for Social Sciences version 19. A $p$ value $<0.05$ was considered statistically significant in the analysis.

\section{Results}

The study respondents' characteristics are provided in Table 1. The majority of respondents were females (59.2\%), nurses (65.8\%), younger than 41 years old (80.4\%), holding a bachelor's or higher degree (76.2\%), with the experience more than five years $(71.8 \%)$ in the profession, and work in shifts $(68.3 \%)$. Moreover, most of them $(78.7 \%)$ worked in medium or large sized ( $\geq 75$ beds) hospitals, the primary departments in which they regularly worked were medical/ surgical (21.7\%), followed by emergency $(20.4 \%)$, more than one department $(11.7 \%)$, pediatrics $(10.8 \%)$, and dialyses (10\%).

\section{Incidence of workplace violence}

In the 12 months prior to the survey, $80.4 \%$ of the respondents reported exposure to workplace violence. Of them, $20.8 \%$ reported exposure to physical violence, $59.6 \%$ reported non-physical violence that included $38.3 \%$ verbal abuse, $19.6 \%$ threats, and $1.7 \%$ sexual harassment. Meanwhile, $16.7 \%$ reported exposure to both physical and non-physical violence in the past 12 months (Table 2).

\section{Associations between exposure to violence and respondents' characteristics}

Table 3 shows the descriptive association between respondents' characteristics and exposure to physical
Table 1 Characteristics of the respondents $(n=240)$

\begin{tabular}{|c|c|c|}
\hline Characteristic & $\mathrm{N}$ & $\%$ \\
\hline \multicolumn{3}{|l|}{ Gender } \\
\hline Male & 98 & 40.8 \\
\hline Female & 142 & 59.2 \\
\hline \multicolumn{3}{|l|}{ Profession } \\
\hline Physician & 82 & 34.2 \\
\hline Nurse & 158 & 65.8 \\
\hline \multicolumn{3}{|l|}{ Age groups } \\
\hline$\leq 30$ years & 89 & 37.1 \\
\hline $31-40$ years & 104 & 43.3 \\
\hline 41-60 years & 47 & 19.6 \\
\hline \multicolumn{3}{|l|}{ Years of experience } \\
\hline $1-5$ years & 68 & 28.3 \\
\hline 6-10 years & 87 & 36.3 \\
\hline $11-15$ years & 45 & 18.8 \\
\hline Above 16 years & 40 & 16.7 \\
\hline \multicolumn{3}{|l|}{ Level of education } \\
\hline Diploma 2 years & 57 & 23.8 \\
\hline Bachelor's & 163 & 67.9 \\
\hline Graduate studies & 20 & 8.3 \\
\hline \multicolumn{3}{|l|}{ Work in shifts } \\
\hline Yes & 164 & 68.3 \\
\hline No & 76 & 31.7 \\
\hline \multicolumn{3}{|l|}{ Hospital size } \\
\hline Small, $<75$ beds & 51 & 21.3 \\
\hline Medium, $75-150$ beds & 109 & 45.4 \\
\hline Large, $>75$ beds & 80 & 33.3 \\
\hline \multicolumn{3}{|l|}{ Department } \\
\hline Medical/Surgical & 52 & 21.7 \\
\hline Emergency & 49 & 20.4 \\
\hline Pediatrics & 26 & 10.8 \\
\hline Split time more than one department & 28 & 11.7 \\
\hline Dialyses & 24 & 10.0 \\
\hline Intensive care & 22 & 9.2 \\
\hline Operating/Recovery Room & 14 & 5.8 \\
\hline Other department & 25 & 10.4 \\
\hline
\end{tabular}

and nonphysical violence in the past 12 months. The results indicated that males $(27.6 \%)$ had a significantly higher percentage of exposure to physical violence than females $(P=0.033)$, however, there was no significant difference in relation to reported non-physical violence by gender. Similarly, those whose education level was below bachelor's degree reported a significantly higher percentage of physical violence incident $(P=0.022)$, but there was no significant difference in the percentage of non-physical violence in relation to the participants' education level $(\mathrm{P}=0.062)$. Respondents who had less than 10 years of experience reported a significantly higher 
Table 2 Incidence of exposure to workplace violence $(n=240)$

\begin{tabular}{|c|c|c|c|c|c|c|c|c|c|c|c|c|}
\hline \multirow{3}{*}{$\begin{array}{l}\text { Exposure to } \\
\text { violence }\end{array}$} & \multirow{2}{*}{\multicolumn{2}{|c|}{$\begin{array}{l}\text { Physical } \\
\text { assault }\end{array}$}} & \multicolumn{8}{|c|}{ Non-physical } & \multirow{2}{*}{\multicolumn{2}{|c|}{$\begin{array}{l}\text { Overall } \\
\text { incidence }\end{array}$}} \\
\hline & & & \multicolumn{2}{|c|}{ Threats } & \multicolumn{2}{|c|}{ Verbal } & \multicolumn{2}{|c|}{ Sexual } & \multicolumn{2}{|c|}{ Total non-physical } & & \\
\hline & $\mathbf{N}$ & $\%$ & $\mathbf{N}$ & $\%$ & $\mathbf{N}$ & $\%$ & $\mathrm{~N}$ & $\%$ & $\mathrm{~N}$ & $\%$ & $\mathrm{~N}$ & $\%$ \\
\hline Yes & 50 & 20.8 & 47 & 19.6 & 92 & 38.3 & 4 & 1.7 & 143 & 59.6 & 40 & 16.7 \\
\hline No & 190 & 79.2 & 193 & 80.4 & 148 & 61.7 & 236 & 98.3 & 97 & 40.4 & 200 & 83.3 \\
\hline
\end{tabular}

percentage of both physical $(\mathrm{P}=0.001)$ and non-physical $(\mathrm{P}<0.001)$ violent incidents compared to respondents who had more years of experience. No significant differences were found in the percentages of reported physical or non-physical violent incidents and respondents' age, profession, work in shifts, or hospital department $(\mathrm{P}>0.05)$.

Table 4 shows the results of the unadjusted and multivariate-adjusted odds ratios for the exposure to violence (yes/ no) with their 95\% confidence intervals according to the different characteristics of the respondents. Unadjusted crude odds ratios analysis indicates that exposure to violence incidents was significantly associated with respondents who were younger than 30 years old $(\mathrm{P}=0.01)$, who had less than 10 years of experiences in the health sector $(\mathrm{P}<0.001)$, and who had less than a bachelor's degree of educational level $(\mathrm{P}=0.022)$.
In comparison, the multivariate-adjusted odds ratios model shows that only two respondents' characteristics remained significantly associated with exposure to work violence (Table 4). In particular, respondents who had less than 10 years of experience were 8 times more likely to be victims of violent incidents than those who had more experience $(\mathrm{P}<0.001)$. Also, respondents who had less than bachelor's degree level of education were almost 3 times more likely to be victims of violent incidents than those who had a higher educational level $(\mathrm{P}=0.01)$.

\section{Characteristics of perpetrators}

Table 5 shows the characteristics of perpetrators by type of violence. The respondents described perpetrators of physical violence as mainly males (76\%), less than 36 years $(88 \%)$, not impaired $(58 \%)$ or impaired due to

Table 3 Characteristics of exposures to physical and non-physical violence in the last 12 months $(n=240)$

\begin{tabular}{|c|c|c|c|c|c|c|c|c|}
\hline & \multicolumn{4}{|c|}{ Physical violence } & \multicolumn{4}{|c|}{ Non-physical violence* } \\
\hline & $\bar{N}$ & $\%$ & $x^{2}$ & $\overline{P \text {-value }}$ & $\bar{N}$ & $\%$ & $x^{2}$ & P-value \\
\hline \multicolumn{9}{|l|}{ Gender } \\
\hline Male & 27 & 27.6 & 4.532 & 0.033 & 52 & 53.1 & 2.926 & 0.087 \\
\hline Female & 23 & 16.2 & & & 91 & 64.1 & & \\
\hline \multicolumn{9}{|l|}{ Age } \\
\hline$\leq 30$ years & 21 & 23.6 & 0.654 & 0.419 & 59 & 66.3 & 2.644 & 0.104 \\
\hline$>30$ years & 29 & 19.2 & & & 84 & 55.6 & & \\
\hline \multicolumn{9}{|l|}{ Profession } \\
\hline Physician & 19 & 23.2 & 0.413 & 0.521 & 51 & 62.2 & 0.353 & 0.553 \\
\hline Nurse & 31 & 19.6 & & & 92 & 58.2 & & \\
\hline \multicolumn{9}{|l|}{ Education } \\
\hline$<$ Bachelor's degree & 18 & 31.6 & 5.234 & 0.022 & 40 & 70.2 & 3.483 & 0.062 \\
\hline$\geq$ Bachelor's degree & 32 & 17.5 & & & 103 & 56.3 & & \\
\hline \multicolumn{9}{|l|}{ Experience } \\
\hline$\leq 10$ years & 42 & 27.1 & 10.410 & 0.001 & 115 & 74.2 & 38.793 & $P<0.001$ \\
\hline$>10$ years & 8 & 9.4 & & & 28 & 32.9 & & \\
\hline \multicolumn{9}{|l|}{ Work in shifts } \\
\hline Yes & 37 & 22.6 & 0.937 & 0.333 & 96 & 58.5 & 0.236 & 0.627 \\
\hline No & 13 & 17.1 & & & 47 & 61.8 & & \\
\hline \multicolumn{9}{|l|}{ Department } \\
\hline Inpatient & 30 & 18.6 & 1.435 & 0.231 & 95 & 59.0 & 0.068 & 0.795 \\
\hline Outpatient & 20 & 25.3 & & & 48 & 60.8 & & \\
\hline
\end{tabular}

* Nonphysical violence includes threats, verbal abuse and sexual harassment.

$x^{2}$ : Pearson Chi-Square Test. 
Table 4 Un-adjusted and multivariate-adjusted odds ratios for exposure to violence among respondents

\begin{tabular}{|c|c|c|c|c|c|c|}
\hline & \multicolumn{2}{|c|}{ Unadjusted } & \multirow[t]{2}{*}{ P-value } & \multicolumn{2}{|c|}{ Adjusted* } & \multirow[t]{2}{*}{ P-value } \\
\hline & OR & $95 \% \mathrm{Cl}$ & & OR & $95 \% \mathrm{Cl}$ & \\
\hline \multicolumn{7}{|l|}{ Gender } \\
\hline Male & 0.76 & $0.88-2.56$ & 0.135 & 0.66 & $0.35-1.23$ & 0.195 \\
\hline Female & 1.0 & Reference & & 1.0 & Reference & \\
\hline \multicolumn{7}{|l|}{ Age } \\
\hline$\leq 30$ years & 2.11 & $0.27-0.84$ & 0.010 & 0.81 & $0.37-1.71$ & 0.572 \\
\hline$>30$ years & 1.0 & Reference & & 1.0 & Reference & \\
\hline \multicolumn{7}{|l|}{ Profession } \\
\hline Physicians & 1.53 & $0.42-1.3$ & 0.292 & 1.65 & $0.82-3.35$ & 0.163 \\
\hline Nurses & 1.0 & Reference & & 1.0 & Reference & \\
\hline \multicolumn{7}{|l|}{ Experience } \\
\hline$<10$ years & 7.05 & $0.08-0.26$ & 0.001 & 8.03 & $3.91-16.47$ & 0.001 \\
\hline$\geq 10$ years & 1.0 & Reference & & 1.0 & Reference & \\
\hline \multicolumn{7}{|l|}{ Education } \\
\hline$<$ Bachelor's degree & 2.3 & $0.22-0.86$ & 0.016 & 2.94 & $1.29-6.67$ & 0.010 \\
\hline$\geq$ Bachelor's degree & 1.0 & Reference & & 1.0 & Reference & \\
\hline \multicolumn{7}{|l|}{ Department } \\
\hline Inpatient & 0.8 & $0.71-2.2$ & 0.451 & 0.75 & $0.39-1.45$ & 0.393 \\
\hline Outpatient & 1.0 & Reference & & 1.0 & Reference & \\
\hline
\end{tabular}

* Adjusted for independent variables: Gender, profession, experience, education, age, and department. OR: Odds ratios, Cl: Confidence interval, Reference: reference category in the logistic regression model.

illness or prescribed medications (38\%), perpetrators were mainly patient visitors/ relatives $(48 \%)$, followed by patients/ clients (38\%), and co-workers (14\%) (including supervisors, physicians, nurses, others). In comparison, non-physical violence, perpetrators were mainly females (63.6\%), of older age (36-60 years) (44.1\%), not impaired
(53.8\%), and patients' relatives (42\%), coworkers (37.1\%), and patients/clients (21\%).

\section{Magnitude and consequence of violent events}

The results relating to the magnitude of the violent incidents showed that the majority of the participants

Table 5 Characteristics of perpetrators associated with physical and non-physical violence

\begin{tabular}{|c|c|c|c|c|}
\hline & \multicolumn{2}{|c|}{ Physical assailant } & \multicolumn{2}{|c|}{ Non-physical assailant* } \\
\hline & $\mathbf{N}$ & $\%$ & $\mathbf{N}$ & $\%$ \\
\hline \multicolumn{5}{|l|}{ Gender } \\
\hline Male & 38 & 76.0 & 52 & 36.4 \\
\hline Female & 12 & 24.0 & 91 & 63.6 \\
\hline \multicolumn{5}{|l|}{ Age group } \\
\hline$\leq 18$ years & 18 & 36.0 & 31 & 21.7 \\
\hline $19-35$ years & 26 & 52.0 & 49 & 34.3 \\
\hline $36-60$ years & 6 & 12.0 & 63 & 44.1 \\
\hline \multicolumn{5}{|l|}{ Impaired perpetrators } \\
\hline Yes, under the influence of illness or prescribed medicines & 18 & 36.0 & 35 & 24.5 \\
\hline Yes, under influence of other drugs or alcohol & 1 & 2.0 & 10 & 7.0 \\
\hline Not impaired & 29 & 58.0 & 77 & 53.8 \\
\hline Not sure & 2 & 4.0 & 21 & 14.7 \\
\hline \multicolumn{5}{|l|}{ Relationship with perpetrators/ sources of violence } \\
\hline Patient/ clients & 19 & 38.0 & 30 & 21.0 \\
\hline Visitors/ patient relatives & 24 & 48.0 & 60 & 42.0 \\
\hline Co-workers (supervisors, physicians, nurses, others) & 7 & 14.0 & 53 & 37.1 \\
\hline
\end{tabular}

* Nonphysical violence includes threats, verbal abuse and sexual harassment. 
reported exposure to a single violent physical (78\%) and non-physical (71.3\%) events; repeated events were respectively $22 \%$ and $28.7 \%$. With regard to the timing of physical assaults, $48 \%$ of them happened in the evening, $20 \%$ in the night, $26 \%$ in the morning, and $6 \%$ were unsure about the time. Non-physical violence mainly (86\%) happened face to face, $8.4 \%$ indicated through phone conversation and $5.6 \%$ by other means. Aggression mainly occurred in office stations (22\%), patients' rooms (14\%), hallways (14\%), and in the reception/ waiting area $(10 \%)$.

The most frequent consequences of physical violence were anger (44\%), depression (22\%), fear or stress (14\%), headache/ fatigue (8\%), and frustration (6\%). In nonphysical violence consequences were anger (50.3\%), headache/ fatigue (18.2\%), depression (12.6\%), and frustration $(8.4 \%)$ (Table 6). Victims of physical assault were mainly treated by physicians $(28 \%)$, psychiatrist $(8 \%)$, or self treated (18\%) and $46 \%$ received no treatment. Whereas for non-physical assault a large percentage had no treatment $(62.9 \%)$, self treated $(30 \%)$, or received psychiatric treatment (4.9\%). While, 18\% whom experienced

Table 6 Characteristics and consequences of violent assault

\begin{tabular}{llllll}
\hline & \multicolumn{2}{c}{ Physical } & & \multicolumn{2}{c}{ Non-physical* } \\
\cline { 2 - 3 } & $\mathbf{N}$ & $\%$ & & N & $\%$ \\
\hline Symptoms/ feelings & & & & \\
\hline Anger & 22 & 44.0 & 72 & 50.3 \\
\hline Depression & 11 & 22.0 & 18 & 12.6 \\
\hline Fear/stress & 7 & 14.0 & 6 & 4.2 \\
\hline Headaches/ fatigue & 4 & 8.0 & 26 & 18.2 \\
\hline Frustration & 3 & 6.0 & 12 & 8.4 \\
\hline Irritability & 2 & 4.0 & 3 & 2.1 \\
\hline Difficulty in sleeping & 0 & 0.0 & 10 & 7.0 \\
\hline None & 3 & 6.0 & 9 & 6.3 \\
\hline Treatment by who & & & & \\
\hline No treatment & 23 & 46.0 & 90 & 62.9 \\
\hline Physician & 14 & 28.0 & 3 & 2.1 \\
\hline treat my self & 9 & 18.0 & 43 & 30.1 \\
\hline Psychiatrist & 4 & 8.0 & 7 & 4.9 \\
\hline Persistent problems as a result & & & \\
\hline Yes & 9 & 18.0 & 45 & 31.5 \\
\hline No & 41 & 82.0 & 98 & 68.5 \\
\hline Work changes as a result & & & & \\
\hline No changes & 26 & 52.0 & 85 & 59.4 \\
\hline Transfer to another location & 6 & 12.0 & 7 & 2.9 \\
\hline Restrictions & 8 & 16.0 & 26 & 10.8 \\
\hline Oeave of absence & 16.0 & 15 & 6.2 \\
\hline Nother & 4.0 & 10 & 4.2 \\
\hline
\end{tabular}

* Nonphysical violence includes threats, verbal abuse and sexual harassment. physical violence reported persistent health problems as a result of the event, and $31.5 \%$ whom experienced nonphysical violence reported persistent problems. Moreover, $48 \%$ of the victims of physical violence reported subsequent changes in their work status including restrictions in work (16\%), work absences (16\%) or transferred to another location (12\%), and $59.2 \%$ of the victims of nonphysical violence reported similar changes (Table 6).

With regard to reporting violent events, $56.3 \%$ of the respondents did not report the incident, $20.4 \%$ of them orally reported to direct supervisors and $19.2 \%$ reported in writing. Of those who did not report the events, $32.5 \%$ indicated they did so because it was useless, from their experience no action would be taken, $20.8 \%$ indicated that it was not important, $20 \%$ were afraid of negative consequences or fear of feeling guilty or ashamed (14.6\%), and lastly $10 \%$ did not know to whom they should report.

The majority of respondents (60\%) indicated absence of procedures for reporting the violence, or any encouragement to report events (59\%). Most of them also indicated that the hospitals had no specific policy/procedure or training programmes against workplace violence (85$95 \%)$. Only $13 \%$ indicated receiving training on any of the following issues: safety measures, dealing with violence, communication, or stress management. A very low percentage indicated availability of violence preventing policies/ procedures related to verbal abuse (18.3\%), health and safety (16.6\%), physical violence (12.5\%), threat $(12.5 \%)$, and sexual harassment (10.4\%).

The respondents were also asked about the measures that exist in the work environment to deal with violence. The most frequently rated safety measures were the following: security personnel (75.4\%), security alarms (36\%), video monitoring systems (26.3\%), cell phones (15\%), and metal detectors (8.3\%).

\section{Discussion}

The main finding of the study was that $80.4 \%$ of the participants indicated exposure to workplace violence in the past 12 months. Despite some differences in the definition of violence, targeted professional groups, and methodology used, the study results are comparable with previous regional and international studies. In general, health workers in the Palestinian public hospitals have higher rate of exposure (80.4\%) to both physical (20\%) and non-physical violence (59.6\%) than many other country studies $[3,5,6,10,11,17]$. The fact that the majority of respondents were exposed to some type of violence is also a matter of concern. Although this study did not investigate the perceived reasons for violence, we hypothesize that the high level of violence against health workers can be explained by the current state of public services including understaffing and inadequate working 
conditions, frequent shortages of medicines and supplies, overcrowded hospitals and delays in receiving care as well as unmet patient needs/expectations [13,14]. Furthermore, this situation is exacerbated, as the study results indicated, by lack of violence preventing strategies such as policy/procedures, training, and lack of adequate safety measures to protect health workers from violence in Palestinian public hospitals. Evidence from other studies showed that such conditions and factors can result in violence against health workers [5,17-19]. The dominant political instability and fragile economic conditions of the country could be other important causative factors. Difficult living conditions, frustration and stress in the daily life of Palestinians life probably increase the aggressive behavior against health workers; however, these factors were not examined in this study. AbuAlRub and colleagues [7] reported much higher level of violence against nurses in Iraq during political violence and economic instability. Increased violence against physicians in Israeli hospitals was also attributed to the deterioration of the economic and security situation [18].

In this study, physicians were slightly more exposed to violence than nurses, although, the difference was not statistically significant $(\mathrm{P}>0.05)$. A study in Turkey [19] also showed the higher exposure of physicians to violence compared to other professions, but conversely in a study from Saudi Arabia nurses were significantly more exposed than physicians [9]. Culturally the medical profession in the Palestinian society is highly valued and dominant, which may account for this difference. Additionally, for that reason patients and relatives may hold higher expectations from physicians, dissatisfaction with health care can expose physicians to aggression more than other health care team members.

Certain characteristics have been found to increase the risk of workers being targets of workplace violence in the healthcare setting, including the workers' gender, age, years of experience, marital status, and previous workplace violence training [20]. In this study, inconsistent with other studies in Lebanon, Egypt, and Saudi Arabia $[6,10,11]$, no significant differences in the overall exposure to violence between males and females were found. However, males exposure to physical violence in general was significantly higher than females $(\mathrm{P}<0.05)$. This was consistent with other studies from Arab countries in the region $[5,10,11]$ and can be attributed to prevalent cultural norms rejecting disrespect to females in these societies. The logistic regression analysis, and in line with other studies $[5,10,11,17]$ revealed that respondents with less experience in health sector and those with lower educational level were significantly associated with exposure to violence $(\mathrm{P}<0.05)$. Other studies provided evidence that as the age of health workers increased, the frequency of violence committed against them decreased
$[5,10,11,17]$. In this study, although significant association was found between respondents age groups and exposure to violence $(\mathrm{P}<0.05)$, however, after adjustment by multiple logistic regression this association became insignificant $(\mathrm{P}>0.05)$.

Detailed data on perpetrators were gathered in the study. Physical violence was mainly perpetrated by males of younger ages, and mainly those not impaired by illness, medications or substances. In comparison nonphysical violence was mainly perpetrated by females of older age and mainly unimpaired persons. Available evidence show that men are more likely and physically capable of enacting physical violence than women who are more likely to enact verbal violence $[11,16,20]$. Also we can infer from our results that most of these incidents contained intentional violence and aggressive behaviors without perpetrators being under influence of disease or substances.

When we look at the magnitude of violence we can see that the majority were single events. Assaults were most likely $(68 \%)$ to happen in the evening and night shifts (2 pm-8 am). Similar results were reported in studies in the region for examples Kuwait, Iraq, Saudi Arabia, and Egypt $[5,7,9,10]$. Higher rates of violence during this time can be also attributed to lower presence of hospital administration, and shortening of staff during the evening and night shifts that would require personnel to work alone [20]. Overloaded work demands place stress on human resources which would also increase conflict with patients and visitors. Consistence with research from Minnesota [16], most of the nonphysical violence occurred face to face (86\%) and in places where staff, patients, and relatives were in direct contact $(60 \%)$ such as office stations, patients' rooms, hallways, and reception/ waiting areas. This denotes inadequate communication skills between providers and recipients of care and weakness in dealing with violent acts or in how to engage the patients and families.

Many studies recognized emergency department as a particularly violent environment [21,22]. In the present study, not surprising, most of the events $(28 \%$ of the physical and $24 \%$ of the non-physical assaults) happened in the emergency departments. These departments are usually attended by aggressive and stressed patients/ visitors and those patients who are impaired by substances who are more likely to commit violence against health workers $[16,21,22]$.

Similar to many of the previous studies the patient relatives' and patients were frequently reported as the main source of violence $[3,7,9,11,16,17,19]$. Nevertheless, a matter of concern was the proportion of violence created by colleagues or supervisors. About $14 \%$ of respondents who encountered physical violence and $37 \%$ encountered non-physical incidents from their 
co-workers specifically from physicians. This was found to be higher than some previous studies $[6,11,16]$. Understaffing, job stress, low job satisfaction are among possible factors that might lead to aggression towards colleagues and co-workers in Palestinian hospitals. Miedema and colleagues [23] found that victims of co-worker violence reported a loss of confidence in their clinical abilities and this subsequently influenced their mental well being [3]. In addition, the co-workers and colleagues violence has negative consequences on team cooperation and on the safety of patient care.

The magnitude of violence in Palestinian public hospitals represented in the frequency of exposure to more than one violent event during the past year (at least $22 \%)$ was higher than found in previous studies $[5,16]$. Moreover, $18 \%$ who experienced physical and $31.5 \%$ who experienced non-physical violence reported persistent problems as a result of the event. About half of those exposed did not receive any kind of treatment. This should be a matter of concern, especially as evidence shows that work related violence usually results in short and long term effects on the victims' physical, psychological state, and professional performance $[19,20]$. Not surprisingly, most of the respondents indicated psychological and emotional feelings such as anger, fear, depression, stress and frustration. Other studies [24,25] showed that individuals who experience nonphysical violence, and endure feelings/symptoms over time, may be at risk for adverse mental health outcomes such as acute stress disorder or post-traumatic stress syndrome. In fact, about half of those who experienced physical or non-physical violence reported subsequent changes in their work status including restrictions in work, absence or subsequent transfer to another location. Apparently, this was much higher than the available evidence showed $[9,16]$. Attention should be given to violence deterrent policies and measures at the workplace as well as enforcement of the legal system after such events.

Low violence reporting level in this study (56.3\%) was similar to previous studies $[3,5,7,11,16,17,19,26]$. The respondents attributed their reluctance to report due to lack of clear procedures for reporting and management encouragement to report. Respondents believed that reporting is useless because hospital management will not take any action besides, the fear of consequences such as blame or revenge of perpetrators. However, it is believed that socio-cultural norms and values of Palestinian society have a great impact. From experience it is known that in many cases incidents are not formally reported and disputes are settled through the tribal system rather than going to the court. Moreover, in many cases health workers consider this as part of the job, therefore tolerating the assailants, and do not feel that they should support reporting the events. The $\mathrm{MoH}$ should strengthen the incident reporting system in public hospitals and enforce laws to deter assaults against health workers as well as raising awareness in the community, and empower staff to cope with and report violence.

The study has some limitations, although a representative random sampling was used, due to time and resource restrictions, the study was limited to 5 public hospitals in the West Bank. Therefore these results may not be generalized to the whole hospital sector in Palestine. Moreover, the study used a retrospective self-reporting approach in data collection. This method depends on the ability of the participants to recall events in last 12 months previous to study, which might have potential biases.

\section{Conclusions}

This study employed a comprehensive approach to identify the incidence, magnitude, consequences and potential risk factors for workplace violence against physicians and nurses in Palestinian public hospitals. The $\mathrm{MoH}$ needs to introduce policy and strategies for prevention and management of workplace violence, enhancement of incident reporting and follow up on reported events as well as providing adequate physical and psychological support to victims of health workplace violence. There is a need to encourage reporting and follow up on incidents as well as providing adequate physical and psychological support to victims of health workplace violence. The results of the study can serve the development of appropriate policy and strategies on workplace violence against health workers and also can serve as the basis for future studies in the country. Further research on workplace violence in other sectors, and on causes of violence in health care settings are needed.

\section{Abbreviations}

$\mathrm{MoH}$ : Ministry of Health; WB: West Bank.

\section{Competing interest}

The authors declare that they have no competing interests.

\section{Authors' contributions}

MK has made substantial contributions to the conception and design of the study, acquisition of data, analysis and interpretation of the data, and drafting the manuscript.

$\mathrm{MH}$ has supervised the study. He also has made substantial contributions to conception and design, analysis and interpretation of data, and drafting the manuscript. Both authors have given final approval of the version to be published.

\section{Acknowledgement}

We acknowledge the Palestinian Ministry of Health cooperation and permission to conduct the study at public hospitals. We also gratefully acknowledge the participants for devoting their time to complete the survey. Finally, thanks go to Mrs. Suzy Dhaher for the English revision.

Received: 22 May 2012 Accepted: 18 December 2012

Published: 20 December 2012 


\section{References}

1. ILO/ICN/WHO/PSI: Framework Guidelines for Addressing Workplace Violence in the Health Sector. Geneva: ILO/ICN/WHO/PSI Joint Programme on Workplace Violence in the Health Sector; 2002.

2. Cooper C, Swanson N: Workplace Violence in the Health Sector - State of the Art. Geneva: ILO/ICN/WHO/PSI Joint Programme on Workplace Violence in the Health Sector; 2002.

3. di Martino V: Workplace Violence in the Health Sector - Country Case Studies (Brazil, Bulgaria, Lebanon, Portugal, South Africa, Thailand, and an Additional Australian Study), Synthesis Report. Geneva: ILO/ICN/WHO/PSI Joint Programme on Workplace Violence in the Health Sector; 2002.

4. Gates DM: The epidemic of violence against healthcare workers Editorial. Occup Environ Med 2004, 61:649-650.

5. Adib SM, Al-Shatti AK, Kamal S, El-Gerges N, Al-Raqem M: Violence against nurses in healthcare facilities in Kuwait. Int J Nurs Stud 2002, 39:469-478.

6. Deeb M: Workplace Violence in the Health Sector - Lebanon Country Case Study. Geneva: ILO/ICN/WHO/PSI Joint Programme on Workplace Violence in the Health Sector; 2003.

7. AbuAIRub RF, Khalifa MF, Habbib MB: Workplace violence among Iraqi hospital nurses. J Nurs Scholarsh 2007, 39:281-288.

8. Abu Ali N: Violence in emergency departments in Palestine: prevalence and prevention. In Proceedings of the First International Conference on Violence in the Health Sector: 22-24 October 2008. Edited by Needham I, Kingma M, O'Brien-Pallas L, McKenna K, Tucker R, Oud N. Amsterdam: Kavanah, Dwingeloo \& Oud Consultancy; 2008:180 [http://www. oudconsultancy.nl/Resources/Proceedings_Workplace_Violence_2008.pdf].

9. El-Gilany $\mathrm{AH}$, El-Wehady $\mathrm{A}, \mathrm{Amr} \mathrm{M}$ : Violence against primary health care workers in Al-Hassa. Saudi Arabia. J Interpers Violence 2010, 25:716-734.

10. Abbas MA, Fiala LA, Abdel Rahman AG, Fahim AE: Epidemiology of workplace violence against nursing staff in Ismailia Governorate. Egypt. J Egypt Public Health Assoc 2010, 85:29-43.

11. Algwaiz WM, Alghanim SA: Violence exposure among health care professionals in Saudi public hospitals: a preliminary investigation. Saudi Med J 2012, 33:76-82.

12. Hamdan M, Defever M: A 'transitional' context for health policy development: the Palestinian case. Health Policy 2002, 59:193-207.

13. Palestinian Health Information Centre: Health Annual Report- Palestine 2011. Nablus: Ministry of Health; 2012 [http://www.moh.ps/attach/440.pdf].

14. Hamdan $M$, Defever $M$, Abdeen Z: Organizing health care within political turmoil: the Palestinian case. Int J Health Plann Manage 2003, 18:63-87.

15. ILO/ICN/WHO/PSI: Workplace Violence in the Health Sector - Country Case Studies Research Instrument- Survey Questionnaire. Geneva: ILO/ICN/WHO/PSI Joint Programme on Workplace Violence in the Health Sector; 2002.

16. Gerberich S, Church T, McGovern P, Hansen H, Nachreiner N, Geisser M, Ryan A, Mongin S, Watt G: An epidemiological study of the magnitude and consequences of work related violence: the Minnesota Nurses' Study. Occup Environ Med 2004, 61:495-503.

17. Ayranci U, Yenilmez C, Balci Y, Kaptanoglu C: Identification of violence in Turkish health care settings. J Interpers Violence 2006, 21:276-296.

18. Carmi-lluz T, Peleg R, Freud T, Shvartzman P: Verbal and physical violence towards hospital- and community-based physicians in the Negev: an observational study. BMC Health Serv Res 2005, 15:54.

19. Erkol H, Gökdoğan MR, Erkol Z, Boz B: Aggression and violence towards health care providers-a problem in Turkey? J Forensic Leg Med 2007, 14:423-428.

20. Gillespie GL, Gates DM, Miller M, Howard PK: Workplace violence in healthcare settings: risk factors and protective strategies. Rehabil Nurs 2010, 35:177-184.

21. Fernandes CM, Bouthillette F, Raboud JM, Bullock L, Moore CF, Christenson JM, Grafstein E, Rae S, Ouellet L, Gillrie C, Way M: Violence in the emergency department: a survey of health care workers. CMAJ 1999, 161:1245-1248.

22. Alameddine M, Kazzi A, El-Jardali F, Dimassi H, Maalouf S: Occupational violence at Lebanese emergency departments: prevalence, characteristics and associated factors. J Occup Health 2011, 9:455-464.

23. Miedema B, Tatemichi S, Hamilton R, Lambert-Lanning A, Lemire F, Manca DP, Ramsden VR: Effect of colleague and coworker abuse on family physicians in Canada. Can Fam Physician 2011, 57:1424-1431.
24. Ryan JA, Poster EC: The assaulted nurse: short-term and long-term responses. Arch Psychiatr Nurs 1989, 3:323-331.

25. Levin PF, Hewitt JB, Misner ST: Insights of nurses about assault in hospitalbased emergency departments. Image J Nurs Sch 1998, 30:249-254.

26. Erickson L, Williams-Evans SA: Attitudes of emergency nurses regarding patient assaults. J Emerg Nurs 2000, 26:210-215.

doi:10.1186/1472-6963-12-469

Cite this article as: Kitaneh and Hamdan: Workplace violence against physicians and nurses in Palestinian public hospitals: a cross-sectional study. BMC Health Services Research 2012 12:469.

\section{Submit your next manuscript to BioMed Central and take full advantage of:}

- Convenient online submission

- Thorough peer review

- No space constraints or color figure charges

- Immediate publication on acceptance

- Inclusion in PubMed, CAS, Scopus and Google Scholar

- Research which is freely available for redistribution

Submit your manuscript at www.biomedcentral.com/submit
C) BioMed Central 